Hispania Sacra, LX

121, enero-junio 2008, 331-354, ISSN: 0018-215-X

\title{
LA RECOMPOSICIÓN RELIGIOSA EN LA MODERNIDAD: UN MARCO CONCEPTUAL PARA COMPRENDER EL ENFRENTAMIENTO ENTRE LAICIDAD Y CONFESIONALIDAD EN LA ESPAÑA CONTEMPORÁNEA
}

\author{
POR \\ JOSEBA LOUZAO VILLAR* \\ Universidad del País Vasco/Euskal Herriko Unibertsitatea
}

\section{RESUMEN}

El presente artículo propone una reflexión teórica sobre el enfrentamiento entre clericales y anticlericales, prestando especial atención a la Restauración. Por ello, examina de forma crítica las múltiples revisiones a las que se ha visto sometido el paradigma de la secularización durante las dos últimas décadas. Asimismo, intenta establecer un marco de análisis novedoso para la aplicación en estudios de caso de herramientas conceptuales tales como recomposición religiosa, conflicto normativo o guerra cultural. En definitiva, se trata de una primera aproximación a un debate historiográfico necesario sobre el papel de la religión en la España contemporánea.

PALABRAS CLAVE: España (siglos XIX-XX), Secularización, Recomposición religiosa, Catolicismo, Anticlericalismo.

\section{ABSTRACT}

This article proposes a theoretical reflection on the conflict between clerical and anticlerical forces and pays main attention to the Restoration period. For that reason, it examines in a critical way the many revisions in which the paradigm of secularization has been left to scholars for the last two decades. Also, it tries to establish an innovative framework of analysis for a new application of conceptual

\footnotetext{
* Este artículo no hubiese podido llevarse a cabo sin la beca Predoctoral del Gobierno Vasco. Asimismo, estas reflexiones forman parte de la investigación que estamos desarrollando bajo el título de Identidad, catolicismo y modernización en la Vizcaya de la Restauración.
} 
tools such as religious recomposition, normative conflict and cultural war in case studies. In short, this is the first approach to a needed historiographical debate on the role of religion in contemporary Spain.

KEY WORDS: Spain (19-20th century), Secularization, Religious recomposition, Catholicism, Anticlericalism.

Recibido/Received 07-08-2007

Aceptado/Accepted 23-11-2007

Durante la última década, los estudios sobre el anticlericalismo, y posteriormente, sobre el clericalismo, se han consolidado dentro de la historiografía española no sólo de forma cuantitativa, sino también -y es lo más destacablecualitativamente. Para hacernos una idea de la situación bastará comparar la «escasez y fragmentación» de la bibliografía sobre este fenómeno, a la que se refería en $1994 \mathrm{M}^{\mathrm{a}}$ Pilar Salomón Chéliz, con la imagen de un desierto floreciente que dibujaba Julio de la Cueva Merino diez años más tarde ${ }^{1}$. Por tanto, este trabajo no procederá a elaborar un estado de la cuestión, ya que existen buenos balances a los que nos remitimos, sino explicar el enfrentamiento entre laicidad y confesionalidad desde una perspectiva diferente e integrada en los debates teóricos sobre la religión en el mundo contemporáneo².

La primera parte de este artículo intenta resumir y describir someramente la evolución del paradigma de la secularización, así como los planteamientos críticos que se han ido estableciendo a lo largo de las últimas décadas, llegándose a desarrollar incluso un paradigma alternativo. En la segunda, trataremos de establecer las claves en los que se asienta la recomposición religiosa en la modernidad y su concreción en la historia española, prestando especial atención a la Restauración. No se debe obviar que bajo esta mirada, que procura ser coherente, se pretende delimitar un aspecto parcial de la fragmentación múltiple del hecho religioso en la transición hacia el mundo moderno. Por tanto, detrás de abundantes temas tratados en este trabajo, se encuentran problemas historiográficos que aún esperan un tratamiento monográfico y otros, los más elaborados, siguen despertando el interés y la discusión abierta en la historiografía reciente.

Evidentemente, es imposible agotar en estas breves páginas los muchos problemas que se derivan de este proceso. El objetivo de este artículo es recorrer brevemente las diferentes posiciones actuales sobre el lugar de la religión

1 El entrecomillado en SAlomón ChÉliz (1994). Poco después NAVArRo (1996), en un balance poco citado en la bibliografía sobre la temática, se refería al anticlericalismo como una cuestión olvidada en nuestra historiografía. La imagen citada en CUEVA MERINO (2004) que es el más reciente estado de la cuestión.

2 Además de los tres balances antes citados es interesante el de PÉREz LEDESMA (2001), sin olvidar dos más antiguos como son los de Cruz (1997) y Cueva Merino (1991) que también destacaban el vacío historiográfico sobre el tema.

Hispania Sacra, LX

121, enero-junio 2008, 331-354, ISSN: 0018-215-X 
en el mundo contemporáneo. Hoy se necesita una reflexión teórica en relación a los conceptos aplicados por la historiografía, en ocasiones peligrosamente erráticos, para continuar desentrañando la complejidad del hecho religioso en la modernidad. Más si se tiene en cuenta que el catolicismo es uno de los ingredientes principales para repensar y revisar la historia contemporánea española, a pesar de la relativamente escasa atención que la historiografía le ha prestado hasta fechas recientes, si se tiene presente su influencia política y social.

Se pretende, en definitiva, incorporar al análisis historiográfico estos conceptos: recomposición religiosa, conflicto normativo y guerra cultural, pues nos parecen herramientas útiles para integrar en una la interpretación histórica global el enfrentamiento entre laicidad y confesionalidad. La renovación teórica a nivel internacional, como puede observarse en un repaso interdisciplinario de la abundante bibliografía, nos ha llevado a esta primera aproximación para establecer un marco conceptual novedoso y ensayar una relectura teórica del conflicto entre clericales y anticlericales que ha jalonado a lo largo de los dos últimos siglos la historia contemporánea española.

\section{LA SECULARIZACIÓN Y SUS CRÍTICOS}

Los estudios y querellas académicas sobre la secularización son inabarcables e interminables ${ }^{3}$. En la actualidad este concepto está cargado de múltiples significados. Es un término ambivalente y multidimensional, como lo describiría Karel Dobbelaere, un defensor clásico del paradigma ${ }^{4}$. En parte por esa causa, desde hace décadas el paradigma de la secularización ha venido siendo matizado y criticado. Tanto es así que muchos investigadores han decidido considerar la secularización como un mito ${ }^{5}$. Reinhart Koselleck llegó a escribir que la secularización «se ha convertido hoy en un eslogan amplio y difuso, so-

\footnotetext{
${ }^{3}$ Quizá tanto que la gran mayoría de los debates nos llegan sesgados y aún hay escasísimas obras traducidas, aún no existen muchas traducciones de análisis ya clásicos, como por ejemplo, la importantísima aportación de Hans Blumenberg en este debate. Sólo hay que mirar las referencias, casi en exclusiva en otros idiomas, de los dos artículos citados en la nota siguiente. Por otra parte, no deja de ser extraño la laxitud de manejo del término en la historiografía española, como si estos debates no existieran.

${ }^{4}$ DobBelaere (1985) y (2002). Sobre el paradigma de la secularización puede verse un amplio resumen en BRUCE (2002:1-44). Desde la historiografía española dos artículos que tratan de resumir la evolución del proceso de secularización en la contemporaneidad son ALONSO (2003) y ÁLVAREZ TARDío (1998). También el libro clásico de CHADwick (1993) y el más reciente de McLeod (2000).

${ }^{5}$ Véase Estruch (1994). Pero quizá el caso más sorprendente sea el de Harvey Cox, quien fuera uno de los teólogos de la secularización más activos, declara ahora que «el mito de la secularización está muerto», contradiciendo su posición de hace unas décadas (Cox 2000:13).
} 
bre cuyo uso apenas es posible alcanzar un acuerdo» ${ }^{6}$. Por todo esto, no nos parece exagerado afirmar que la secularización como concepto explicativo resulta inoperante para el estudio de la religiosidad en perspectiva histórica. Porque, ¿de qué hablamos cuando nos referimos a un término tan polisémico como secularización?

Saeculum, en el latín eclesiástico, significó mundo desde que San Jerónimo realizara la Vulgata en el siglo V. Tuvo desde entonces una fuerte connotación negativa, ya que se refería al mundo que rechazó Jesucristo, convirtiéndose así, con el tiempo, en un concepto contrapuesto a Iglesia.

Se utilizó como término jurídico a fines del XVI en Francia dentro de debates canónicos para definir el tránsito de un religioso regular al estado secular. Así lo hicieron canonistas como Jean Papon o Pierre Grégoire. Este significado se conserva hasta la actualidad en el derecho canónico. Con la Paz de Westfalia pasará a expresar el tránsito de los bienes eclesiásticos a manos seculares, siendo introducida en las negociaciones de dicho acuerdo por el legado francés Longueville.

Encarnaba una dicotomía entre lo espiritual y lo terrenal, lo sagrado y lo profano. Al mismo tiempo, se incardinaba en el pensamiento católico bebiendo de la idea de los dos reinos de San Agustín. Marramao habla de pares paulinos. De ese modo estructuró la historia medieval occidental, sirviendo para distinguir entre el mundo y la Iglesia ${ }^{7}$. Estas raíces religiosas explican que Hans Blumenberg no aceptara la secularización. Se enfrentó a la conocida tesis del teólogo protestante Friedrich Gogarten: la secularización había sido una consecuencia del cristianismo. Para Blumenberg la modernidad no adquiere su legitimidad a través del pensamiento cristiano, sino de la autoafirmación humana conquistada frente a la fe medieval, una modernidad liberadora con la metáfora del giro copernicano como centro de la misma ${ }^{8}$.

Aunque para los fundadores de la ciencia moderna en el siglo XVII, no existió un conflicto excluyente entre razón y fe, sí lo hubo con la Ilustración, si bien en el caso alemán fue mucho menos crítica con la religión ${ }^{9}$. Se iniciará un proceso de erosión de la religión con la búsqueda de la autonomía del individuo frente a la tradición, y de la emancipación de la razón cientificista frente a la fe.

\footnotetext{
${ }^{6}$ Koselleck (2003:41). Otros, como Diotallevi (2001:16), hablan de old paradigm para referirse a la secularización. Por eso mismo, llama la atención poderosamente que recientemente Miguel Requena haya escrito que «la secularización sigue disfrutando, en general, de bastante buena salud» (el subrayado es nuestro). REQUENA (2005:318).

7 Sobre la evolución histórica del término resultan imprescindibles MARRAMAO (1998) y KosELLECK (2003).

${ }^{8}$ El libro del pensador alemán, aún no traducido al castellano, Die Legitimität der Neuzeit se publicó en el año 1966. Para esta discusión filosófica GALINDO HERVÁs (2006).

${ }_{9}$ Sobre las diferencias entre Ilustraciones MATTHES (1971:58-67).
}

Hispania Sacra, LX

121, enero-junio 2008, 331-354, ISSN: 0018-215-X 
La Revolución Francesa iniciará una enconada disputa política en relación al lugar de la Iglesia en el mundo moderno. El pastor protestante Samuel Vincent, en Vues sur le protestantisme en France (1829), anunció que sería «la labor del siglo XIX y su coronación» ${ }^{10}$. Durante el ochocientos algunos influyentes pensadores europeos, como Feuerbach, Marx y Engels, ahondaron en esa línea, creyendo ver en la religión uno de los más importantes obstáculos hacia el progreso, la autonomía y la libertad.

La Iglesia católica también tomó sus posiciones. La constitución dogmática sobre la fe católica Dei Filius del Vaticano I, del 20 de abril de 1870, supeditaba la razón a la fe. El avance del racionalismo se entendía como una apostasía que desencadenaría una catástrofe.

En definitiva, se estaban asentando las bases de lo que más adelante, a fines del siglo XIX, se comenzaría a definir como secularización. Desde sus orígenes, con Auguste Comte y su actitud ante la religión, la sociología planteó el presente y el futuro de la religión con presupuestos heredaros del discurso ilustrado. Pese a que no utilizó el término habitualmente, resulta bastante evidente que Max Weber explicitó el concepto ${ }^{11}$. El «desencantamiento el mundo», una racionalización con raíces primero judías y posteriormente cristianas, sirve para vehicular sus ideas sobre la religión en la modernidad.

El desencantamiento se produce por la pérdida de la fe del hombre moderno en la búsqueda de explicaciones transcendentes o mágicas. De igual forma, la evolución de la historia, según Weber, mostraba que se iba a producir la irremediable separación entre el poder civil y las instituciones religiosas ${ }^{12}$.

Para completar este sucinto cuadro sobre los orígenes del concepto, hay que señalar que los primeros sociólogos norteamericanos serán una excepción en esta descripción, pues aún pesaba demasiado en ellos la herencia puritana constitutiva de la sociedad americana y sólo más tardíamente, en las primeras décadas del siglo XX, comenzarán a sustituir la «teodicea» que les había inspirado hasta entonces ${ }^{13}$.

\footnotetext{
${ }^{10}$ Cfr. en Gauchet (2003:53). Una síntesis de este enfrentamiento político en el continente europeo en RÉMOND (1999).

${ }_{11}$ Max Weber se crió en un entorno familiar, perteneciente a la burguesía adinerada alemana, dominado por la religiosidad de su madre. Tras la muerte de su padre comenzará un viaje por España, que se detendrá en Burgos, desde donde retornará a su país. Su cultura protestante no pudo soportar un ambiente católico como el español que le disgustó enormemente. La carta que le envía a su madre desde el Abra bilbaíno, donde describe la religiosidad que observó en la villa, es una muestra de ese enfrentamiento. La carta puede verse en WEBER (1997).

12 WeBER (1983). En realidad, su análisis es mucho más rico y abierto de lo aquí planteado, pero no tenemos el suficiente espacio para entrar en matizaciones.

13 Véase VIDICH y LYMAN (1985:1-5).
} 
«El siglo XXI será religioso o no será». La frase, supuestamente atribuida a André Malraux, aunque negó en una entrevista poco antes de morir haberla pronunciado, no dejaba de ser más que una polémica boutade pseudo-profética de intelectual. La gran mayoría la creyó de imposible cumplimiento en la Europa de posguerra mundial. En esta coyuntura se desarrollará plenamente el paradigma de la secularización, como explicación de la evolución de la religión en el mundo contemporáneo, bajo el influjo de las ideas weberianas y de Emile Durkheim ${ }^{14}$.

El canon de la secularización podría resumirse en tres puntos y una conclusión: 1) la secularización implica la pérdida de influencia de la religión en la sociedad moderna, que muchos calificaron de declive, así como el retroceso de las prácticas y creencias religiosas; 2) un proceso de privatización de la religión ${ }^{15}$ unido a la diferenciación y autonomía de las distintas esferas; 3 ) se produce el desencantamiento del mundo, es decir, la desacralización y mundanización de la realidad. Conclusión: modernidad y religión entraban por tanto en inevitable contradicción, produciéndose la fragmentación y marginalización de la fe que conlleva la pérdida de la influencia de las instituciones religiosas.

Los datos empíricos parecían demostrar un retroceso continuo de la religión en la modernidad, irreversible e imparable. Retomando en parte algunas de las ideas de Gogarten, surgirán dos respuestas, ambas procedentes del campo teológico protestante: una teología de la secularización, que pretendía buscar la manera de hablar de Dios de una forma secular, y una efímera teología de la muerte de Dios (Death-of-God-theology), que intentaba sostener un ateísmo cristiano ${ }^{16}$. Como explica Richard Vinen, «fue una época en la que sociólogos, economistas y, en grado mucho menor de lo que suelen admitir, los historiadores creyeron en la eficacia de grandes modelos explicativos» ${ }^{17}$. La secularización no entraba en contradicción con ninguno de ellos.

Se puede observar que la secularización se había convertido en una narrativa asumida en los medios académicos. Peter L. Berger lo ha definido recientemente como «club de cultura universitaria» (faculty club culture $)^{18}$. Muchos científicos sociales vivían en una torre de marfil secularizante aceptando el discurso ilustrado sin preocuparse por los datos empíricos que demostrasen sus aseveraciones. Nada extraño, si entendemos que la comunidad científica se había construido enfrentándose a la religión y por la autonomía secular del conocimien-

\footnotetext{
14 DURKHEIM (2003).

15 La religión invisible de la que habló LUCKMAN (1973).

16 Una magnífica síntesis de ambos proyectos teológicos, así como la visión de la secularización desde la teología cristiana, en GiBELLINI (1998:133-163).

17 VINEN (2002:15).

18 BERger (2004:65).
}

Hispania Sacra, LX

121, enero-junio 2008, 331-354, ISSN: 0018-215-X 
to ${ }^{19}$. Un club militante que observará como una rémora del pasado y del arcaísmo, más que como un problema teórico, cualquier fenómeno religioso que desencajaba de ese proceso teleológico en que se convirtió la secularización, como correlato de la modernización ${ }^{20}$. Hubo ya entonces voces, como la de David Martin, que discutieron la secularización. Prefirieron suprimirla de sus análisis, aunque al final se mantendrán, matizadamente, dentro del paradigma ${ }^{21}$.

Por un lado, ni Estados Unidos, ni los países de asiáticos de industrialización tardía parecen demostrar que modernización y secularización vayan unidos, sino más bien al contrario. Incluso, defensores del paradigma, como Peter L. Berger, han dado marcha atrás refiriéndose en la actualidad al fenómeno de la desecularización del mundo, con la excepción europea ${ }^{22}$. No en vano, en los años ochenta se produjeron diferentes movimientos de reafirmación religiosa, musulmanes, judíos y cristianos. Con una ideología comunitarista buscarán la revitalización religiosa de la sociedad frente al laicismo y una modernidad a la que descalificaban ${ }^{23}$. Como ha señalado José Casanova, la religión se hizo pública en esa década, iniciada en 1979, con la revolución islámica iraní y el triunfo sandinista en Nicaragua ${ }^{24}$.

A Casanova se debe una de las redefiniciones del paradigma de la secularización más sugerentes, centrada en el papel público de la religión en la modernidad $^{25}$. Observa que la religión ha estado, de una forma u otra, presente en la mayor parte de los conflictos de fin del siglo XX. Es decir, estos sucesos políticos le permiten afirmar que se está produciendo una desprivatización de la religión contra la tesis mantenida por el canon secularizador. Según él, sólo el planteamiento de la diferenciación es acertado y es constitutivo de la modernidad. Sin embargo, tanto la privatización como la caída de la práctica religiosas, son tesis erróneas, pues no se han producido como presuponía el paradigma de la secularización.

19 HERVIEU-LÉGER (2005:34).

${ }^{20}$ Como señala Hervieu-LÉGER (2005:27-28), los científicos sociales dedicados a la religión fueron vistos con cierta desconfianza, como si fuera imposible conseguir un distanciamiento crítico con el objeto de estudio si de materia religiosa se trataba. Y tenemos la sensación que es una postura aún presente en la historiografía española, entre otras razones porque «no se acaba de dar el salto cualitativo desde la historia eclesiástica a la historia religiosa». MONTERO (2003:267).

21 Martin (1978).

22 BERger (1999b:9-11). Se refiere en realidad a dos excepciones, por un lado, la Europa occidental, y por otro, la elite cultural occidental y globalizada. Steve BRUCE (2001:87), firme defensor de la secularización, ha afirmado incluso que Berger se está confesando de un pecado que no ha cometido.

${ }^{23}$ KEPEL (2005). Aunque en el libro sólo trate de las tres «religiones del Libro», lo cierto, como el propio Kepel reconoce, es que sus conclusiones podrían darse también para el caso del hinduismo o del shintoismo.

24 Casanova (2000:15).

25 Ibidem (2000). 
Los datos empíricos sobre las prácticas y las creencias religiosas parecen desmentir las predicciones. Las tendencias demuestran que la religión no está decayendo en el mundo moderno, salvo quizá en Europa occidental, aunque el propio Harvey Cox en uno de sus últimos libros cree que los europeos, al fin y al cabo, tampoco son una excepción al despertar religioso que recorre el mundo ${ }^{26}$. En Europa, la realidad es bastante más compleja de lo que parecen mostrar las encuestas. Por ejemplo, nos encontramos con la creencia sin pertenencia (believing without belonging ${ }^{27}$, un fenómeno moderno de la creencia en un Dios, sin por ello pertenecer a ninguna de las religiones, produciéndose un alejamiento de la ortodoxia institucional al que se refiere Grace Davie, que ha estudiado la transformación religiosa en la sociedad europea de fines del siglo XX. En algunos sitios, como en Escandinavia, hay un proceso contrario: participar sin creer.

En paralelo, nos encontramos con los denominados Nuevos Movimientos Religiosos (NMRs), vulgarmente conocidos como sectas ${ }^{28}$, surgidos en los años sesenta en Estados Unidos, y poco después trasladados a Europa. Dentro de los NMRs, encontramos toda una amalgama de movimientos, ligados la gran mayoría de ellos a la espiritualidad alternativa del movimiento New Age, que van desde el culto a los ovnis, hasta cultos orientales, sincréticos, esotéricos o con pretendidas raíces cientifistas. Pero también aparecen grupos como los pentecostales, en sus vertientes protestante y católica, que han crecido ampliamente en América Latina en las últimas décadas.

Dicho esto, cabe poner en cuarentena también la asunción, a veces irreflexiva, de muchos científicos sociales cuando admiten la situación actual de la religión, a veces con afirmaciones grandilocuentes, como el despertar o el retorno de lo sagrado, lo que en el fondo no es tal. La religiosidad siempre ha estado presente, sea de una forma institucionalizada o no ${ }^{29}$. No se debe olvidar que ese mundo de la racionalidad técnica y científica de la industrialización trajo consigo no sólo el alejamiento de las iglesias, sino una búsqueda de la salvación por otros canales. Desde el espiritismo a la videncia, pasando por la teosofía de Helena Blavatsky y los más diversos movimientos ocultistas, hubo una verdadera «huida al irracionalismo». Hay que añadir la exótica atracción, y redescubrimiento, de los maestros espirituales y la sabiduría oriental que comenzó en esta época ${ }^{30}$. Muchas de estas

${ }^{26}$ Cox (1995).

27 DAVIE (1999:71).

${ }^{28}$ Sobre los NMRs, VernetTe (1996) y Díez DE Velasco (2000)

${ }^{29}$ Pueden verse, en este sentido, los seis puntos con los que concluye su artículo Brown (1992:55-56).

${ }^{30} \mathrm{El}$ entrecomillado es de James Webb, citado por LINSE (2002:2). Sobre el budismo en Europa LÉNOIR (2001). Sobre la teosofía, además del libro citado anteriormente, WASHINGTON (1995) y para España y sus implicaciones con los movimientos sociales en el siglo XIX POMÉs VIVES (2006). Un análisis sobre el espiritismo en la España del XIX ABEND (2004), la Cataluña de fines del siglo XIX en HORTA (2004) y sobre género y espiritismo en RAMOS (2005).

Hispania Sacra, LX

121, enero-junio 2008, 331-354, ISSN: 0018-215-X 
realidades han sido tratadas por los historiadores como fenómenos marginales y anecdóticos, pero su expansión por Europa y Norteamérica, a pesar de lo limitado del alcance de algunos de estos movimientos, demostró que la religiosidad no se agotaba en la práctica institucionalizada.

Existe una última crítica dirigida por los historiadores especializados en las áreas geográficas no occidentales contra el arrogante eurocentrismo- cristiano de los pilares que sustentan la secularización. Tomemos por ejemplo la sugerente síntesis del siglo XIX que ha elaborado C. A. Bayly. En ella, encontramos la afirmación de que el ochocientos fue el siglo de «la triunfal reemergencia y expansión de la religión» ${ }^{31}$. El siglo que va de 1815 a la Primera Guerra Mundial asistió a la expansión y la consolidación de las llamadas religiones mundiales, que se convirtieron en imperiales, aunque la gran mayoría de los contemporáneos no fueron capaces de observar lo que estaba sucediendo. Este proceso tiene una importancia similar al avance del liberalismo o al surgimiento del nacionalismo, ya que se encargó de transformar al judaísmo, al islam, al hinduismo o al budismo, reformulados en respuesta al asalto misionero cristiano. El catolicismo también tuvo que reaccionar ante el fuerte impulso evangelizador del protestantismo, del que en ocasiones tomaron formas y métodos de evangelización. Las reflexiones de Bayly y otras importantes aportaciones de la historiografía dedicada al mundo no occidental invitan a criticar y matizar el paradigma de la secularización y analizar el lugar de la religión en la modernidad desde una perspectiva más global y comparativa ${ }^{32}$.

Todas estas críticas han hecho tambalear el tradicional paradigma de la secularización y replantear algunos de sus postulados. Eso sí, muchos de los críticos, en especial los europeos, siguen usando la conceptualización heredada y, a pesar de sus deficiencias, no desechan por completo el paradigma. No obstante, desde la década de los noventa, científicos sociales norteamericanos, descontentos con las tesis de la secularización, comenzaron a desarrollar un paradigma alternativo, denominado teoría económica de la religión ${ }^{33}$. En él se mantiene que la diferenciación, parte constitutiva del mundo moderno, ha participado activamente en la transformación religiosa durante la edad contemporánea.

${ }^{31}$ BAYLY (2004:325). No en vano la hiperinflación nominativa del siglo XIX, como siglo del liberalismo, de la industrialización, del nacionalismo, de la democracia, etc. es una prueba palpable de la complejidad histórica, y de los peligros de privilegiar, jerarquizando, ciertos sujetos en detrimento de otros.

${ }^{32}$ No en vano, creemos, aunque una nota a pie de página no sea el lugar adecuado para profundizar en ello, que estas miradas nos pueden permitir reelaborar y matizar las teorías sobre el nacionalismo y su surgimiento - otro tanto podríamos decir de transferencia de sacralidad en la política moderna-, muy dependientes de una lectura unidimensional del fenómeno religioso en el mundo contemporáneo. ¿Realmente fue el nacionalismo el Dios de la modernidad?

${ }^{33}$ Un buen resumen sobre este paradigma en FRIGERIO (2000). 
Este nuevo paradigma, inspirado en la experiencia histórica y presente de los Estados Unidos, tiene al sociólogo Rodney Stark ${ }^{34}$ como uno de sus principales defensores. Con esta novedosa y radical visión de la religión en la modernidad se ha conseguido introducir en el análisis del hecho religioso la elección racional y conceptos de la teoría económica, como monopolio, desregulación, mercado ${ }^{35}$, consumidores, etc. Este paradigma establece que lo natural es una separación entre estado e iglesia, es decir, la diferenciación dentro de una sociedad dominada por el pluralismo, aunque puedan existir y hayan existido monopolios regulados por el estado. Asimismo, estos autores piensan que cuanto mayor sea el pluralismo dentro de una sociedad más alta será la participación religiosa. Incluso, llegan a defender que los puntos de partida históricos del paradigma de la secularización son erróneos, ya que en la época medieval era la indiferencia, y no la fe, lo dominante en materia religiosa.

No es de extrañar, por tanto, que estas ideas descansen sobre los conceptos de la oferta y la demanda y la crítica a la presunción irracionalista de los comportamientos religiosos. Para sus defensores, las creencias religiosas posibilitarían la obtención de recompensas imposibles de conseguir por medios mundanos.

Stark afirma que la demanda se mantiene constante en el tiempo y, por lo tanto, debemos explicar el cambio religioso a través de la oferta. Son, en definitiva, los cambios de la oferta de las instituciones religiosas los que influyen en los comportamientos religiosos de las personas. Están relacionados con la oferta de productos atrayentes o no ${ }^{36}$.

Los datos que avalan esta teoría son norteamericanos, aunque también intenta extrapolar el modelo a otros lugares, como América Latina. No creen en la secularización, sino en la desacralización de la sociedad debido al pluralismo en el mercado religioso. Explicado de otra forma, se produce una diferenciación que no repercute en la importancia y el lugar que ocupa la religión en cada persona. De hecho, la diferenciación social conlleva una individualización y ésta a una personalización del consumo.

Estas revisiones de los postulados centrales del paradigma de la secularización pueden servirnos para comenzar a elaborar un marco interpretativo alternativo, intentando escapar del punto muerto que ofrecen estos debates en el vie-

${ }^{34}$ Entre sus obras destacar el premio Pulitzer StARK (2001) o STARK y BAINBRIDGe (1996).

${ }^{35} \mathrm{El}$ concepto de mercado también es utilizado por el propio Peter L. Berger. Sobre el complejo desarrollo a lo largo del tiempo de la teoría sociológica de la religión de Berger, el libro conjunto WOODHEAD (ed.) (2001).

${ }^{36}$ Esta última idea quizá no sea tan novedosa, como a primera vista puede parecer, ya que estaba implícita en algunas de las críticas que desde la propia iglesia se hacía de la pastoral católica en las primeras décadas del siglo XX. Véase en este sentido, por ejemplo, el análisis sobre los arrabales bilbaínos de Zabala y ALLENDE (1929).

Hispania Sacra, LX

121, enero-junio 2008, 331-354, ISSN: 0018-215-X 
jo paradigma europeo, que sólo llega explicar, aunque no globalmente, el caso europeo. Ahora bien, tampoco la teoría alternativa del mercado religioso parece tan convincente, si la extraemos de la experiencia estadounidense. Por ello, nos unimos a las voces que defienden un análisis amplio, comparativo y global para, en última instancia, lograr sostener un nuevo paradigma más abierto. Somos conscientes de la dificultad del empeño, porque quizá ningún modelo puede ayudarnos a reunir todas las piezas interpretativas del complejo puzzle de la religión en la modernidad ${ }^{37}$.

\section{LA RECOMPOSICIÓN RELIGIOSA EN LA MODERNIDAD}

La modernidad, como hemos visto, no está enfrentada a la religión, aunque la relación entre ambas sea compleja y dinámica. Algunos investigadores se han referido a una metamorfosis para describir los cambios producidos respecto al hecho religioso durante la modernidad ${ }^{38}$. Nos parece más oportuno caracterizar este proceso como una recomposición de la religión en la modernidad. Con ello pretendemos atender a las ambivalentes transformaciones religiosas que se producen, ya que las instituciones religiosas, se adaptarán a ella, como recuerda Diotallevi: la religión sucumbe a la modernidad solamente si no se moderniza ella misma ${ }^{39}$, pero también resistirá duramente, si se siente asediada por ella. A partir de estos cambios, no exentos de contradicciones, podemos referirnos a la conformación a lo largo de los siglos XIX y XX de un sujeto religioso moderno, o si se prefiere, de una nueva forma de creencia individualizada, alejada de la cultura religiosa, dominante hasta entonces, y ahora en una situación de pluralismo religioso ${ }^{40}$.

No entraremos aquí en los ricos debates sobre la definición de la religión ${ }^{41}$. Remarcaremos, tal como hace David Lyon, que entendemos que es fácil concebir erróneamente la religión como una conducta meramente habitual (como ir a la iglesia) o como actividad cognitiva (creencias lógicas), mientras que en realidad también tiene que ver -y más profundamente-con la fe, la identidad y aspectos no cognitivos de la vida, como la emoción» ${ }^{42}$. No en vano, hace ya más

${ }^{37}$ Sobre esta última afirmación, no me resisto a citar lo que sobre los modelos explicativos escribió Charles TILLY (1992:16): «En anteriores investigaciones comprobé una vez y otra que la experiencia española era muy comprensible en sus propios términos, pero no se adaptaba, sin embargo, a las generalizaciones que los analistas políticos extraían de las historias de Inglaterra, Prusia y Francia. Llamar excéntrica a España no tenía sentido; el defecto estaba claramente en la generalización, no en España».

${ }^{38}$ ESTRUCH (1994:280) y LENOIR (2005).

39 Diotallevi (2001:17).

${ }^{40}$ Se pueden ampliar estas ideas en LENOIR (2005:32-45).

${ }^{41}$ Un repaso crítico de las definiciones sociológicas puede consultarse en HERVIEU-LÉGER (2005).

${ }^{42}$ LYON (2002:47). El subrayado es nuestro. 
de una década, Caroline Ford señaló que la historiografía europea debía intentar responder a «cómo la religión contribuyó en la formación de las identidades culturales y de género» ${ }^{43}$. Sin embargo, en la historiografía española sólo en fechas muy recientes se ha comenzado a trabajar en una historia cultural de la religiosidad en la contemporaneidad atenta a la construcción de la identidad ${ }^{44}$.

Sobre esto último, creemos que es interesante y fructífero usar algunas de las conclusiones de Hervieu- Léger, en su análisis sobre la creencia religiosa, vinculándola a la memoria colectiva ${ }^{45}$. Una definición de la creencia religiosa conjuga tres elementos: la expresión de un creer, la memoria de una continuidad y la referencia legitimadora a una versión autorizada de esa memoria, es decir, la tradición. Por tanto, no existe religión que no apele a la autoridad de la tradición. Esta tradición será clave para la construcción de las identidades religiosas en las sociedades modernas, pues, en las tradicionales, al estar regidas por la tradición, la memoria se encuentra dada. No en vano, durante la Restauración, el catolicismo español inventará una tradición ${ }^{46}$. No hay que desdeñar, por tanto, el gran potencial creativo y articulador de la religión en la construcción identitaria y también su capacidad movilizadora ${ }^{47}$.

No debemos obviar, en esta recomposición religiosa, otros dos fenómenos que nos sirven para evaluar continuidades y cambios: la religiosidad popular y la feminización de la religión.

La religiosidad popular es otro de los conceptos confusos para las ciencias sociales, pero la podemos caracterizar como aquellas prácticas religiosas distintas, más que contrarias, a la religión oficial e institucionalizada ${ }^{48}$, y estrechamente ligadas a la cotidianidad de las personas. Atendiendo a ellas, constatamos los límites de la secularización, y se demuestra que tales prácticas fueron mucho más que meros elementos supersticiosos de la religiosidad de amplios sectores de población. Estas expresiones populares se recuperaron y afianzaron a lo largo del siglo XIX, y hasta bien entrado el XX, en todo el mundo católico europeo, a través de procesiones, de la devoción mariana o el uso de exvotos. En España, la Iglesia potenció este tipo de religiosidad para luchar contra la revolución liberal y no perder su ascendiente social.

\footnotetext{
${ }^{43}$ FORD (1993:175).

${ }^{44}$ Una lista cada día más amplia, entre otros, Blasco Herranz (2003) y (2005); Cueva Merino (1997) y (1999a) o SALOMÓN CHÉLIZ (2002b) y (2005).

45 HeRVIEU-LÉGer (2005:154-167 y 201-266).

${ }^{46}$ Siguiendo a Cueva Merino (1999), (2000a) y (2005) usamos aquí la clásica, pero poco reflexionada, fórmula de invención de la tradición de HOBSBAWm y RANGER (eds.) (2002).

${ }^{47}$ Como explica Figuerola (1999:44) «la movilización religiosa es sinónimo de movilización política» en el proceso de recomposición religiosa, añadimos.

48 Véase Castro Alfín (2003). 
La feminización de la religión también se debe insertar en el proceso de recomposición religiosa, un fenómeno que fue duramente criticado por las fuerzas laicistas como una manipulación clerical ${ }^{49}$. El análisis historiográfico sobre esta asociación de mujer y religión se debe en un primer momento a las preocupaciones feministas del mundo anglosajón y protestante, pero ha sido la historiografía francesa la que mejor ha estudiado su desarrollo y evolución ${ }^{50}$. Claude Langlois, uno de los principales investigadores en este campo, en su obra sobre las congregaciones femeninas francesas, cuyas conclusiones son asimilables al caso español, presenta el aumento de la participación religiosa y la piedad de las mujeres ligado a la caída de la práctica religiosa por parte de los hombres, y el incremento del ingreso y número de las nuevas congregaciones religiosas femeninas ${ }^{51}$. Las congregaciones religiosas, sobre todo las femeninas, se convirtieron en elementos dinamizadores del cambio social con una nada desdeñable capacidad modernizadora, como bien han puesto de manifiesto para el caso guipuzcoano Maitane Ostolaza ${ }^{52}$. Tampoco conviene olvidar que la feminización de la religión facilitó la creación de la dicotomía discursiva entre un atraso, identificado con la religión y esta, a su vez, con la feminidad, y la del progreso, ligado al liberalismo, identificado con la masculinidad. De hecho, los orígenes de la secularización como concepto deben rastrearse en esta diferenciación.

En otro orden de cosas, aunque el conflicto también se puede extrapolar a otros países de religión no cristiana, esta recomposición en los países cristianos, en el ámbito occidental, se vio moldeada e influida por un conflicto normativo sobre la posición de las instituciones religiosas en el mundo moderno. En España, una Iglesia católica, que había sido pilar de la sociedad tradicional, pretendía seguir siéndolo ${ }^{53}$. Estas confrontaciones normativas tuvieron desarrollos muy diversos en Europa como consecuencia de las diferentes tradiciones religiosas y de las coyunturas políticas en cada país. En España, la revolución libe-

49 Sobre esas imágenes de la mujer por parte del anticlericalismo SALOMÓn CHÉLIZ (2003). Un ejemplo práctico puede verse en La Lucha de Clases [LC], 16-VII-1904: «iY pensar que la mujer sea el brazo derecho de la religión!» o LC, 2-XI-1907: «La Iglesia que no tiene pelo de tonta, que es una institución muy ladina, con mucho sentido práctico para hacer sobrevivir sus errores, se ha apoderado de la mujer y saca de ella un partido enorme para sus fines de predominio sobre las conciencias y sobre la sociedad».

${ }^{50}$ Blasco Herranz (2005:120-121). No en vano, aunque el fenómeno corrió paralelo en el espacio protestante y católico, sus implicaciones difieren.

51 LANGLOIS (1984). También puede consultarse GiBSON (1989:180-190) o, más recientemente, FORD (2005).

52 Ostolaza (2000).

53 Sobre conflictos normativos el libro editado por BERger (1999a). Sobre la Iglesia Católica se pueden consultar las síntesis de historia de la Iglesia en la edad contemporánea de CALLAHAN (1989) y (2002) o LANNON (1990). 
ral erosionará y transformará la centralidad normativa vigente durante siglos. Esta vinculación política con el poder y su preeminencia social convirtieron el debate sobre el papel de la Iglesia, aunque con diferente grado de intensidad en cada momento, en una de las líneas centrales de la historia contemporánea española hasta la Transición. Se desactivó entonces el conflicto y se llegó a un consenso, no sin problemas, en materia religiosa ${ }^{54}$.

Merece la pena, antes de continuar, precisar lo que entendemos por conflicto normativo. Peter L. Berger intenta resumirlo en dos cuestiones básicas: ¿quiénes somos? y ¿cómo hemos de convivir? ${ }^{55}$ Por tanto, podríamos definirlo como aquel conflicto político- cultural que se produce dentro de cualquier sociedad plural sobre aspectos fundamentales de su propia definición y auto-identificación colectiva. En el ámbito de esta disputa política, donde se dan cita los valores y los intereses de los distintos grupos, divididos a su vez en diferentes subculturas políticas, se irán construyendo las diversas identidades colectivas. Estas no son estables, ni esenciales. Se reconstruyen constantemente.

Así cuanto más opuestas sean las convicciones normativas, la frontera entre ambos grupos se encontrará mejor delimitada con una oposición frontal, en ocasiones de exclusión total del adversario político. No es extraño, teniendo en cuenta que la victoria del contrario significaba no sólo una derrota política, sino una grave amenaza para la pervivencia de la moral y los valores defendidos por el grupo. En momentos concretos de este antagonismo, no es exagerado afirmar, a pesar de las deficiencias conceptuales que se le puedan achacar al término, que se produce una auténtica guerra cultural ${ }^{56}$. No en vano, en estas coyunturas, las organizaciones o instituciones que gestionan el conflicto pueden introducir en la dinámica política el uso de la violencia para demostrar el potencial de su fuerza ${ }^{57}$. Se minimiza entonces el disenso grupal consolidando la cohesión interna y conformando una fuerte vinculación emocional a través de diversos símbolos y rituales. Son múltiples los ejemplos en la España restauracionista, como la violencia desatada durante las peregrinaciones a Begoña de octubre de $1903^{58}$, y los hubo también durante la República.

54 Sobre la Transición puede consultarse CASANOVA (2000).

55 Berger (1999a:520).

56 Véase HunTER (1991). En su polémico estudio, este autor llegó a defender que la extrema polarización de la sociedad norteamericana entre conservadores y liberales -en el sentido que se le concede a la palabra en los Estados Unidos- en cuestiones de definición social y moral se podría caracterizar como una culture war. Una aplicación a los conflictos en relación a la religión en la Europa decimonónica, ClARK y KAISER (eds.) (2003).

57 GonZÁlez CAlleja (2003).

${ }_{58}$ Para este caso, nada excepcional en la época, puede consultarse nuestro trabajo de suficiencia investigadora LOUZAO (2007).

Hispania Sacra, LX

121, enero-junio 2008, 331-354, ISSN: 0018-215-X 
Al hilo de la narración, conviene recordar que esa pérdida de centralidad normativa ocurrió en España durante la primera parte del siglo XIX, aunque la decadencia ya había comenzado a fines del siglo anterior. La Iglesia se convirtió así en uno de los principales enemigos del estado liberal, cuando atacó los privilegios eclesiásticos. Hasta entonces la monarquía hispánica se asentaba en la conocida conjunción entre el Trono y Altar, conformando una monarquía que creía tener una misión divina. La monarquía había sido no accesoriamente sino en esencia católica. La religión había cohesionado la identidad colectiva y revestido a la monarquía de una ideología casticista. Monarquía y religión católica fueron los elementos que aglutinaron a los españoles durante la edad moderna ${ }^{59}$.

Durante el ochocientos el antiliberalismo será predominante en la Iglesia católica española. Recordemos El liberalismo es pecado de Félix Sardà y Salvany, La unión entre el tradicionalismo y la Iglesia constituyó un discurso donde el liberalismo era nocivo, pernicioso y ponía en serio peligro la unidad católica española.

La Iglesia tuvo que aceptar el nuevo orden político liberal al final de la primera guerra carlista. El moderantismo y la Iglesia se aproximaban lentamente y con problemas. El encuentro culminará con la firma del Concordato de 1851. En este proceso de aceptación del régimen liberal, la Iglesia se nacionalizó en la segunda mitad del XIX. La guerra del 98 fue el hito que hizo efectiva dicha transformación. Es decir, no sólo sobrevivió la identidad religiosa católica en España, sino que se reformuló dentro de los parámetros discursivos del nacionalismo. Un nacional-catolicismo, como lo definió el historiador Alfonso Botti, que fundió sustancialmente el catolicismo y la nación, y en el que encontramos figuras tan diversas como Menéndez y Pelayo, Ramiro de Maeztu y organizaciones políticas como Acción Española, que asumieron la modernidad económica, pero no la política ${ }^{60}$. Por tanto, pese a la escasa atención prestada hasta hace bien poco por los estudiosos del nacionalismo, la Iglesia fue un agente nacionalizador de primer orden, a tener en cuenta en el estudio de la construcción de la nación española ${ }^{61}$.

De esa oposición surgirán dos modelos normativos opuestos, con numerosas subculturas políticas también enfrentadas en su interior ${ }^{62}$, incapaces de llegar a un consenso normativo estable en lo referente a la definición de la nación espa-

\footnotetext{
59 Estas ideas están sacadas de Portillo VAldÉs (2006:18-21), Fernández SEBASTIÁN (1994:4853) y ÁlVAREZ JunCo (2001:305-341).

60 BotтI (1992).

61 Véanse las páginas, no siempre acertadas, que al tema dedica Álvarez JunCo (2001).

62 Como con cualquier esquema explicativo, habrá que tomar ciertas precauciones y remarcar la complejidad de la sociedad española a lo largo de los siglos XIX y XX. Por ello, no se pretende agotar todas las tendencias sociopolíticas españolas en una falsa dicotomía generalizadora.
} 
ñola y el lugar del catolicismo en ella. A un lado, los defensores de una definición de España católica creían que cualquier avance de la laicización encaminaba al país a la ruina. Por ello, no es extraño que defendieran una reconquista moral de la sociedad a todos los niveles y denunciaran constantemente los numerosos peligros que minaban los fundamentos sociales de la nación, cuya defensa correspondía a todo católico ${ }^{63}$. Enfrente, las fuerzas que confiaban en el progreso y en la modernización para el desarrollo de una nación atrasada a causa, según defendían, de una Iglesia católica, representante de un pasado que se pretendía borrar, y de las constantes intromisiones clericales en la política y la sociedad española ${ }^{64}$.

Estos dos modelos, el confesional y el defensor de la laicidad, se definirán y articularán nacionalmente durante la Restauración. En otras palabras, entre 1875 y la proclamación de la II República, este conflicto, desarrollado a lo largo de todo el siglo XIX en España, se nacionalizó. No fue ya sólo un enfrentamiento sobre el lugar que debía ocupar la religión en la sociedad, sino sobre la propia definición de la nación española ${ }^{65}$.

La Restauración, en especial el reinado de Alfonso XIII, estuvo marcada por la llamada cuestión religiosa, ya que la restauración monárquica de 1875 facilitó asimismo la restauración de la Iglesia católica, que ya era una institución completamente distinta a la que había iniciado el siglo XIX con una nueva or-

${ }^{63}$ Baste una breve cita del jesuita Remigio VILARIÑo (1903:6-7), a la sazón director de El Mensajero del Corazón de Jesús, para ejemplificarlo: «Contra esta universal irrupción anticristiana todos cuantos tengan amor de Dios son soldados, todos cuantos sientan celo de las almas son apóstoles, toda la Iglesia de la tierra es militante; y por la fuerza misma de las cosas resulta natural, espontánea y necesariamente el apostolado seglar, mediante el cual procuran la salvación de las almas, no tan sólo los sacerdotes y ministros de Dios, sino también todos y cada uno de los fieles cristianos».

64 Por lo que el anticlericalismo y el clericalismo, tal como los entendemos, son dos fenómenos plenamente modernos, que nacen de la pluralidad esencial y constitutiva de la sociedad moderna. Así, podríamos definir el anticlericalismo como la defensa de un modelo social y político laico, ya sea en su variante moderada, que sólo pretende la separación entre estado y la Iglesia católica, como en la más radical que llega a atacar de raíz a la propia religión. Mientras, el clericalismo sería la defensa de un modelo social y político en el que la Iglesia, como institución, formara parte en todos los aspectos de la esfera pública dentro de su propio monopolio religioso. Ambos fenómenos crearán todo un sistema cultural de valores, creencias y de referencia, además de una identidad y, al igual que en Francia, como ha explicado Gabriel MoTzKIN (2000), la polarización entre izquierda y derecha se establecerá y definirá también a partir de la cuestión religiosa. De hecho, al asimilar anticlericalismo con laicización defendemos una interpretación positiva del término, como ya hizo en su momento René RémOND (1985). Aunque esta definición positiva es algo ya habitual en la historiografía, la evidente vinculación existente entre el clericalismo y el anticlericalismo -como modelos normativos enfrentados-, hace que en los análisis prácticos se caiga a menudo sin pretenderlo en la reacción como única explicación, eliminando así la autonomía de discurso y acción del anticlericalismo que sí se defiende en la teoría.

65 Esta nacionalización del conflicto comenzó en el Sexenio, pero se hará efectiva durante las décadas de la Restauración. Un magnífico acercamiento a la vertiente nacionalizadora del conflicto durante la II República en RADCLIFF (1997).

Hispania Sacra, LX

121, enero-junio 2008, 331-354, ISSN: 0018-215-X 
ganización eclesiástica ${ }^{66}$. A pesar de que no todas las esperanzas católicas se vieron cumplidas, ya que la Constitución estableció la tolerancia de culto frente a la unidad católica, la Iglesia acogió el nuevo régimen con alivio tras el Sexenio democrático, aún manteniendo la desconfianza hacia el liberalismo. En las primeras décadas de este periodo en la que el conflicto estuvo latente, mientras se abrían o reformaban seminarios, se cubrían las sedes vacantes, aumentaban las publicaciones periódicas y organizaciones católicas de todo tipo, como sindicatos o asociaciones de seglares, aumentaba el número de religiosos y también los actos de piedad externa. Por el contrario, entre 1901 y 1913, el conflicto entre anticlericales y clericales estalló, aunque ya desde los últimos años del siglo XIX se habían producido algunos enfrentamientos menores, quizá de los más publicitados, junto al escándalo Nozaleda (1904), fue el caso judicial de una joven, la señorita Ubao, que, siendo menor, había ingresado en un convento sin el consentimiento de sus padres y que sirvió a Pérez Galdós para escribir su drama Electra (1901), cuyas representaciones alteraron el orden público en numerosas ocasiones. Desde entonces, los debates, las manifestaciones o los mítines clericales o anticlericales se reprodujeron en toda la geografía española constantemente ante cualquier decisión gubernamental o polémica religiosa ${ }^{67}$.

\section{BIBLIOGRAFÍA}

ABEND, Lisa (2004): «Specters of the Secular: Spiritism in Nineteenth- century Spain», European History Quaterly, 34/4. pp. 507-534.

Alonso, Gregorio (2003): «La secularización de las sociedades europeas», Historia Social, 46, 2003. pp. 137-157.

Álvarez Junco (2001): Mater Dolorosa. La idea de España en el siglo XIX, Taurus, Madrid.

Álvarez TARdío, Manuel (1998): «Política y secularización en la Europa Contemporánea», Studia histórica. Historia Contemporánea, 16. pp. 143-166.

- (2002): Anticlericalismo y libertad de conciencia: política y religión en la Segunda República Española, Centro de Estudios Políticos y Constitucionales, Madrid.

BAYLY, C. A. (2004): The Birth of the Modern World 1780-1914: Global Connections and Comparisons, Blackwell Publishers, Oxford.

${ }^{66}$ La restauración en CUEVA MERINO (2003:288) y la construcción de una nueva organización eclesiástica en ÁlVAREZ TARDío (2002:15).

${ }^{67}$ Para ampliar esta descripción Cueva Merino (1997a), Lannon (1990) o Callahan (2002). 
Berger, Peter L. (1999b): «The Desecularization of the World: A Global Overview», en Berger, Peter L.; The Desecularization of the World. Resurgent Religion and World Politics, Ethics and Public Policy Center, Washington, D.C. pp. 1-18.

- (2004): «Globalización y religión», Iglesia Viva, 218. pp. 63-72.

- (ed.) (1999a): Los límites de la cohesión social. Conflictos y mediación en las sociedades plurales, Galaxia Gutenberg/ Círculo de Lectores, Barcelona [1997].

Blasco Herranz, Inmaculada (2003): Paradojas de la ortodoxia. Política de masas y militancia católica femenina en España (1919-1939), Prensas Universitarias de Zaragoza, Zaragoza.

- (2005): «Género y religión: de la feminización de la religión a la movilización católica femenina. Una revisión crítica», Historia Social, 53. pp. 119-136.

BotтI, Alfonso (1992): Cielo y dinero: el nacionalcatolicismo en España (1881-1975), Alianza. Madrid.

Brown, Callum G. (1992): «A Revisionist Approach to Religious Change», en Bruce, Steve (ed.); Religion and Modernization: Sociologists and Historians Debate the Secularization Thesis, Clarendon Press, Oxford. pp. 31-58.

BRUCE, Steve (2001): «The curious case of the unnecessary recantation: Berger and secularization», en Woodhead, Linda (ed.); Peter Berger and the Study of Religion, Routledge, London. pp. 87-100.

- (2002): God is Dead: secularization in the West, Blackwell Publishing, Oxford.

Callahan, William (1989): Iglesia, poder y sociedad en España, 17501874, Nerea, Madrid.

- (2002): La Iglesia Católica en España (1875-2002), Crítica, Barcelona [2000].

CARO BAROJA, Julio (1980): Introducción a una historia contemporánea del anticlericalismo español, Istmo, Madrid.

Casanova, José (2000): Religiones públicas en el mundo moderno, PPC, Madrid [1994].

CAStro Alfín, Demetrio (1997): «Cultura, política y cultura política en la violencia anticlerical», en Cruz, Rafael y Pérez Ledesma, Manuel (eds.); Cultura y movilización en la España contemporánea, Alianza, Madrid.

- (2003): «La religiosidad popular en España. De la crisis del Antiguo Régimen a la sociedad industrial. Algunas cuestiones para su estudio», en Uría 
Jorge (ed.), La cultura popular en la España Contemporánea. Doce estudios, Biblioteca Nueva, Madrid.

CHADWICK, Owen (1993): The secularization of the european mind in the 19th century, Cambridge University Press, Cambridge [1975].

Clark, C. y KaIser, W. (eds.) (2003): Culture Wars: Secular- Catholic Conflict in Nineteenth- Century Europe, Cambridge, Cambridge University Press.

Cox, Harvey (1995): Fire from Heaven. The Rise of Pentecostal Spiritualy and the Reshaping of Religion in the Twenty-First Century, Addison- Wesley, Reading.

- (2000): «The Myth of the Twentieth Century. The Rise and Fall of Secularization», Japan Journal of Religious Studies, 27/1-2. pp. 1-13.

CruZ, Rafael (1997): «Los estudios sobre anticlericalismo en España al final del milenio», Ayer, 27. pp. 219-229.

Cueva Merino, Julio de la (1991): «La cuestión clerical- anticlerical contemporánea en la historiografía española», en Rueda, Germán (ed.); Doce estudios de historiografía española, Universidad de Cantabria, Santander.

- (1994): Clericales y anticlericales. El conflicto entre confesionalidad y secularización en Cantabria (1875-1923), Universidad de Cantabria/ Asamblea Regional de Cantabria, Santander.

- (1997a): «La democracia frailófoba. Democracia liberal y anticlericalismo durante la Restauración», en Suárez Cortina, Manuel (ed.); La Restauración entre el liberalismo y la democracia, Alianza, Madrid. pp. 229-271.

- (1997b): «Movilización política e identidad anticlerical, 1898-1910», Ayer, 27. pp. 101-126.

- (1999): «Cultura y movilización en el movimiento católico de la Restauración (1899-1913)», en Suárez Cortina, Manuel (ed.); La cultura española en la Restauración, Sociedad Menéndez Pelayo, Santander. pp. 169-192.

- (2000a): «Católicos en la calle: la movilización de los católicos españolas, 1899-1923», Historia y Política, 3. pp. 55-80.

- (2000b): «Si los curas y frailes supieran ... La violencia anticlerical», en Juliá, Santos (ed.); Violencia política en la España del siglo XX, Taurus, Madrid. pp. 191-233.

- (2003): «El rey católico», Moreno Luzón, Javier; Alfonso XIII: un político en el trono, Marcial Pons, Madrid pp. 280-306.

- (2004): «El anticlericalismo en España. Un balance historiográfico», en Pellistrandi, Benoît (éd.), L'histoire religieuse en France et en Spagne, Collection de la Casa de Velázquez, Madrid. pp. 353-370. 
- (2005): «Clericalismo y movilización católica durante la restauración», en Cueva Merino, Julio de la y López Villaverde, Ángel Luis (eds.); Clericalismo y asociacionismo católico en España: de la Restauración a la Transición, Universidad de Castilla- La Mancha, Cuenca. pp. 27-50.

- y LóPEZ VillaVERDE, Ángel Luis (2005): «A modo de introducción. Reflexiones en torno al clericalismo y al asociacionismo católico», en Cueva Merino, Julio de la y López Villaverde, Ángel Luis (eds.); Clericalismo y asociacionismo católico en España: de la Restauración a la Transición, Universidad de Castilla- La Mancha, Cuenca. pp. 17-25.

- y Montero, Feliciano (2000): «Clericalismo y anticlericalismo en torno a 1898: Percepciones recíprocas», Sánchez Mantero, Rafael (ed.); En torno al 98. España en el tránsito del siglo XIX al XX (Tomo II), Universidad de Huelva, Huelva, 49-64.

DAvIE, Grace (1999): «Europe: The Exception That Proves the Rule?», en Berger, Peter L.; The Desecularization of the World. Resurgent Religion and World Politics, Ethics and Public Policy Center, Washington, D.C. pp. 65-83.

Díez de Velasco, Francisco (2000): Las nuevas religiones, Ediciones del Orto, Madrid.

Diotallevi, Luca (2001): Il rompicapo della secolarizzazione italiana. Caso italiano, teorie americane e revisione del paradigma della secolarizzazione, Rubbettino Editore, Soveria Mannelli.

Dobbelaere, Karel (1985): «Secularization Theories and Sociological Paradigms: a Reformulation of the Private- Public Dichotomy and the Problem of Societal Integration», Sociological analysis, 46. pp. 377-387.

Dobbelaere, Karel (2002): Secularization: an Analysis at Three Levels, P.I.E.-Peter Lang, Brussels.

DURKHEIM, Emile (2003): Las formas elementales de la vida religiosa, Alianza, Madrid [1912].

EstruCH, Joan (1994): «El mito de la secularización», en Díaz- Salazar, Rafael, Giner, Salvador y Velasco, Fernando (eds.); Formas modernas de religión, Alianza, Madrid. pp. 266-280.

FERNÁNDEZ SEbASTIÁN, Javier (1994): «España, monarquía y nación. Cuatro concepciones de la comunidad política española entre el Antiguo Régimen y la Revolución liberal», Studia Histórica- Historia Contemporánea, XII. pp. 45-74.

Figuerola, Jordi (1999): «Movimiento religioso, agitación social y movilización política», Historia Social, 35. pp. 43-63.

ForD, Caroline (1993): «Religion and Popular Culture in Modern Europe», Journal of Modern History, 65. pp. 152-175. 
FORD, Caroline (2005): Divided houses: religion and gender in modern France, Cornell University Press, Ithaca.

FRIGERIO, Alejandro (2000): «Teorías económicas aplicadas al estudio de la religión: ¿hacia un nuevo paradigma?, Boletín de Lecturas Sociales y Económicas, 34. pp. 34-50.

GALINDo HerVÁs, Alfonso (2006): «¿Autonomía o secularización? Un falso dilema sobre política moderna», en Mate, Reyes y Zamora, José A. (eds.); Nuevas teologías políticas. Pablo de Tarso en la construcción de Occidente, Anthropos, Barcelona. pp. 117-137.

GAUCHET, Marcel (2003): La religión en la democracia, ElCobre Ediciones/ Universidad Complutense, Barcelona [1998].

GibelLini, Rosino (1998): La Teología del siglo XX, Sal Terrae, Santander [1993].

GiBson, Ralph (1989): A Social History of French Catholicism, 1789-1914, Routledge, London,

GonzÁlez CAlleja, Eduardo (2002): La violencia en la política. Perspectivas teóricas sobre el empleo deliberado de al fuerza en los conflictos de poder, Consejo Superior de Investigaciones Científicas, Madrid.

HERVIEU-LÉGER, Danièle (2005): La religión, hilo de memoria, Herder, Barcelona [1993].

Hobsbawm, Eric J. y RANGER, Terence (eds.) (2002): La invención de la tradición, Crítica, Barcelona [1983].

HORTA, Gerard (2004): «Espiritismo y lucha social en Cataluña a finales del siglo XIX», Historia, Antropología y Fuentes Orales, 31 . pp. 29-49.

Hunter, James Davidson (1991): Culture Wars: The Struggle to Define America, Basic Books, New York.

KePEL, Gilles (2005): La revancha de Dios. Cristianos, judios y musulmanes a la reconquista del mundo, Alianza, Madrid [1991, 2003-2 ${ }^{\mathrm{a}}$ ed.].

KosellecK, Reinhart (2003): Aceleración, prognosis y secularización, PreTextos, Valencia [2000].

La Parra López, Emilio y Suárez Cortina, Manuel (eds.) (1998): El anticlericalismo español contemporáneo, Biblioteca Nueva, Madrid.

LANGLOIs, Claude (1984): Le Catholicisme au féminin. Les congrégations françaises à supérieure générale au XIXe siècle, Les Éditions du Cerf, Paris.

Lannon, Frances (1990): Privilegio, persecución y profecía. La Iglesia en España, 1875- 1975, Alianza, Madrid [1987]. 
LENOIR, Frédéric (2000): El Budismo en Occidente, Seix Barral, Barcelona [1999].

- (2005): Las metamorfosis de Dios. La nueva espiritualidad occidental, Alianza, Madrid [2003].

LINSE, Ulrich (2002): Videntes y milagreros. La búsqueda de la salvación en la era de la industrialización, Siglo XXI, Madrid [1996].

LouZAO, Joseba (2007): El anticlericalismo en la Vizcaya de la Restauración (1898-1912), Trabajo de Suficiencia investigadora inédito.

LucKMAN, Thomas (1973): La religión invisible, Sígueme, Salamanca [1967].

Lyon, David (2002): Jesús en Disneylandia. La religión en la posmodernidad, Cátedra, Madrid [2000].

Marramao, Giacomo (1998): Cielo y tierra. Genealogía de la secularización, Paidós, Barcelona [1994].

Martin, David (1978): A General Theory of Secularization, Basil Blackwell, Oxford.

MATTHES, Joachim (1971): Introducción a la sociología de la religión. I. Religión y sociedad, Alianza, Madrid [1967].

MCLEOD, Hugh (2000): Secularisation in Western Europe, 1848-1914, MacMillan, Hampshire.

Montero, Feliciano (2003): «La historia de la Iglesia y del catolicismo español en el siglo XX. Apunte historiográfico», Ayer, 51. pp. 265-282.

MotzKin, Gabriel (2000): «Secularización, burgueses e intelectuales en Francia y Alemania durante el siglo XIX», en Fradera, Josep María y Millán, Jesús; Las burguesías europeas del siglo XIX, Biblioteca Nueva/ Universitat de València, Madrid.

NAVARRO, F. Javier (1996): «Una qüestió oblidada: l'anticlericalisme a l'Espanya contemporàni», en Martí, Manuel (coord.); D'història contemporània: debats $i$ estudis. Un homenatge casolà a E. P. Thompson (1924-1993), Sociedad Castellonenca de Cultura, Castelló de la Plana. pp. 57-81.

Ostolaza, Maitane (2000): Entre Religión y Modernidad. Los colegios de las congregaciones religiosas en la construcción de la sociedad guipuzcoana contemporánea, 1876-1931, Servicio Editorial de la Universidad del País Vasco, Bilbao.

PéRez Ledesma, Manuel (2001): «Teoría e historia. Los estudios sobre el anticlericalismo en la España contemporánea», en Suárez Cortina, Manuel (ed.); Secularización y Laicismo en la España Contemporánea (III Encuentro de Historia de la Restauración), Sociedad Menéndez Pelayo, Santander.pp. 341-368. 
Pomés Vives, Jordi (2006): «Diálogo Oriente- Occidente en la España de finales de siglo XIX. El primer teosofismo español (1888-1906): un movimiento religioso heterodoxo bien integrado en los movimientos sociales de su época», Revista HMiC, 4. s.p.

Portillo Valdés, José María (2006): Crisis atlántica. Autonomía e independencia en la crisis de la monarquía hispana, Marcial Pons, Madrid.

RADCLIFF, Pamela (1997): «La representación de la nación. El conflicto en torno a la identidad nacional y las prácticas simbólicas en la Segunda República», en Cruz, Rafael y Pérez Ledesma, Manuel (eds.); Cultura y movilización en la España contemporánea, Alianza, Madrid. pp. 305-325.

Ramos, $M^{a}$ Dolores (2005): «Heterodoxias religiosas, familias espiritistas y apóstolas laicas a finales del s. XIX: Amalia Domingo Soler y Belén de Sárraga Hernández», Historia Social, 53. pp. 65-83.

RÉMOND, René (1985): L'Anticlericalisme en France. De 1815 à nos jours, Editions Complexe, Bruxelles.

- (1999): Religion and society in modern Europe, Blackwell Publishers, Oxford.

REQUENA, Miguel (2005): «Religión y sociedad: la secularización de la sociedad española», en González, Juan Jesús y Requena, Miguel (eds.); Tres décadas de cambio social en España, Alianza, Madrid. pp. 315-339.

SALOMÓn CHÉLIz, Ma Pilar (1994): «Política y ética. Balance historiográfico sobre anticlericalismo», Historia Social, 19. pp. 113-128.

- (2001): «Anticlericalismo y movilización política en Aragón (18981936)», Ayer, 41. pp. 189-211.

- (2002a): Anticlericalismo en Aragón. Protesta popular y movilización política, Prensas Universitarias de Zaragoza, Zaragoza.

- (2002b): «El discurso anticlerical en la construcción de una identidad nacional española republicana (1898-1936)», Hispania Sacra, 54. pp. 485-497.

- (2005): «Las mujeres en la cultura política republicana: religión y anticlericalismo», Historia Social, 53. pp. 103-118.

- (2003): «Beatas sojuzgadas por el clero: la imagen de las mujeres en el discurso anticlerical del primer tercio del siglo XX», Feminismo/s, 2. pp. 41-58.

Stark, Rodney (2001): El auge del cristianismo, Andrés Bello, Santiago de Chile [1996].

- y BAINBRIDGE, William Sims (1996): A theory of religion, Rutgers university Press, New Brunswick. 
TiLly, Charles (1992): Coerción, capital y los Estados europeos, 990-1990, Alianza, Madrid.

VernetTE, Jean (1996): Les sectes, Presses Universitaires de France, Paris.

Vidich, Arthur J. y LyMan, Stanford M. (1985): American Sociology. Wordly Rejections of Religion and Their Directions, Yale University, New Haven.

VILARIÑo, Remigio (1903): Apostolado de los seglares: folleto de combate, Imprenta del Corazón de Jesús, Bilbao.

VINEN, Richard (2002): Europa en fragmentos. Historia del viejo continente en el siglo XX, Península, Barcelona [2000].

Washington, Peter (1995): El mandril de Madame Blavatsky, Destino, [1993].

WeBer, Max (1983): Ensayos sobre sociología religiosa, Taurus, Madrid.

Weber, Max (1997): «Carta de Max Weber a Helene Weber», Bidebarrieta, 11. pp. 192-209.

WoodHEAd, Linda (ed.) (2001); Peter Berger and the Study of Religion, Routledge, London.

Zabala y AlLENDE, Federico (1929): Los arrabales de Bilbao y sus necesidades religiosas, Editorial Vizcaína, Bilbao. 